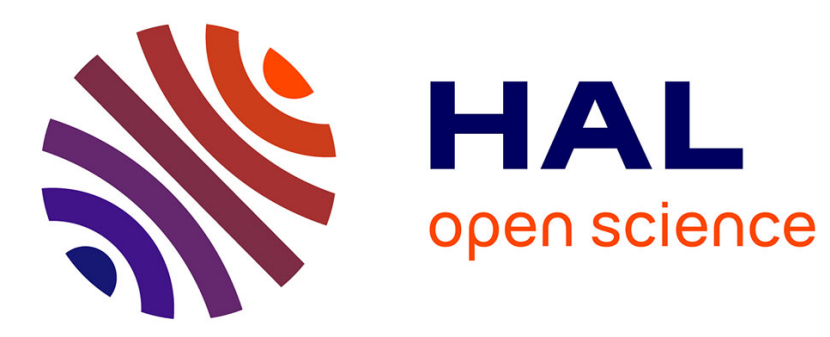

\title{
Anticipatory postural adjustments in a bimanual load-lifting task in children with developmental coordination disorder
}

Marianne Jover, Christina Schmitz, Laurie Centelles, Brigitte Chabrol, Christine Assaiante

\section{To cite this version:}

Marianne Jover, Christina Schmitz, Laurie Centelles, Brigitte Chabrol, Christine Assaiante. Anticipatory postural adjustments in a bimanual load-lifting task in children with developmental coordination disorder. Developmental Medicine and Child Neurology, 2010, 52 (9), pp.850 - 855. 10.1111/j.14698749.2009.03611.x . hal-01772106

\section{HAL Id: hal-01772106 https://hal.science/hal-01772106}

Submitted on 18 May 2018

HAL is a multi-disciplinary open access archive for the deposit and dissemination of scientific research documents, whether they are published or not. The documents may come from teaching and research institutions in France or abroad, or from public or private research centers.
L'archive ouverte pluridisciplinaire $\mathbf{H A L}$, est destinée au dépôt et à la diffusion de documents scientifiques de niveau recherche, publiés ou non, émanant des établissements d'enseignement et de recherche français ou étrangers, des laboratoires publics ou privés. 
[Original Article; 2 figures: 2 tables]

\section{Anticipatory postural adjustments in a bimanual load-lifting task in children with developmental coordination disorder}

MARIANNE JOVER ${ }^{1}$

CHRISTINA SCHMITZ ${ }^{2}$

LAURIEC ENTELLES ${ }^{2}$

BRIGITTE CHABROL ${ }^{3}$

CHRISTINE ASSAIANTE ${ }^{2}$

1 Centre de Recherche en Psychologie de la Connaissance, du Langage et de I'Emotion, Aix-Marseille Université, France. 2 Laboratoire Neurosciences

Intégratives \& Adaptatives. CNRS Aix-Marseille Université, France. $\mathbf{3}$ Unité de Médecine Infantile, CHU Timone Enfants, Marseille, France.

Correspondence to Christine Assaiante at Equipe Développement et Pathologie de I'Action, Pôle3C - Laboratoire Neurosciences Intégratives \& Adaptatives (UMR 6149),Université de Provence \& CNRS, Centre St Charles - Case B, 3 Place Victor Hugo, 13331 Marseille Cedex 03, France.

E-mail:Christine.assaiante@univ-provence.fr

\section{PUBLICATION DATA}

Accepted for publication $23^{\text {rd }}$ November 2009.

Published online 00th Month 2010

\section{LISTOF ABBREVIATIONS}

$\begin{array}{ll}\text { APA } & \text { Anticipatory postural adjustment } \\ \text { DCD } & \text { Developmental coordination disorder } \\ \text { M-ABC } & \text { Movement Assessment Battery for Children } \\ \text { MA } & \text { Maximum angular amplitude } \\ \text { MV } & \text { Maximum velocity }\end{array}$

\section{[Abstract]}


Aim Postural control is a fundamental component of action in which deficits have been shown to contribute to motor difficulties in children with developmental coordination disorder (DCD). The purpose of this study was to examine anticipatory postural adjustments (APAs) in children with DCD in a bimanual load-lifting task.

Method Sixteen children with reported motor problems (two females, 14 males; mean age 9y; SD 2y) and 16 typically developing, age-matched children took part in the study (six females, 10 males; mean age 9y; SD 2y). The task required them to maintain a stable elbow angle, despite imposed or voluntary unloading of the forearm. APAs were assessed using electromyography and kinematics analysis.

Results Although children with DCD could compensate for the consequences of unloading, the results demonstrated that APAs were less efficient in children with $D C D$ than in typically developing children. A positive and significant coefficient of regression between the flexor inhibition latency and the postural stabilization was only found in typically developing children.

Interpretation The impaired fine-tuning of the muscle contribution and the poor stabilization performances demonstrate poor predictive modelling in DCD.

\section{What this paper adds:}

- defines APA impairments in children with DCD in a bimanual load-lifting task;

- links performance during postural stabilization to muscle inhibition latency;

- is in favour of an immature or impaired predictive modelling in children with DCD.

(C)The Authors. Journal compilation (c) Mac Keith Press 2010

DOI: 
Developmental Medicine \& Child Neurology 2010, 52: 000-000

Right page footer

Postural Anticipation in Children with DCD Christine Assaiante et al.

\section{[Text]}

'Developmental coordination disorder' (DCD) is the term used to describe marked clumsiness without any sign of neurological injury, pervasive developmental disorder, or learning disability*. Performances on daily activities that require motor coordination are substantially poorer than expected. DCD may manifest itself inconsiderable delays in achieving motor milestones, poor performance in sports, or poor handwriting. ${ }^{1}$ The clinical picture of the motor impairment is very heterogeneous, with some children presenting with poor gross motor coordination whilst demonstrating proficiency in fine coordination, and vice versa.

Postural deficits have been found in children with DCD. ${ }^{2}$ It has been demonstrated that static postural control in children with DCD relies on a greater amount and more variable patterns of muscular activity than it does in typically developing children of a similar age. ${ }^{3}$ Studies exploring balance during quiet standing have yielded inconclusive results. Although Geuze et al. ${ }^{4}$ failed to find any clear differences between children with and without DCD, other authors have observed a greater centre of pressure sway in children with DCD than in their typically developing peers. ${ }^{5}$ It seems that the former are especially prone to difficulties when placed in novel situations. ${ }^{4}$

*North American usage: mental retardation. 
In more dynamic postural tasks, the differences between children with and without DCD in the fine control of postural adjustments become more obvious. By predicting the possible postural disturbance created by movement performance, anticipatory postural adjustments (APAs) allow the body or one of its segments to maintain stability. ${ }^{6}$ In a forward- and backward-leaning task, Przysucha et al. ${ }^{7}$ observed less efficient postural adaptations in males with DCD than in boys without DCD. Using electromyography (EMG), Johnston et al. ${ }^{8}$ showed that children with DCD demonstrate spatial and temporal impairment of APAs in most of the postural muscles that provide a stable basis when performing a rapid voluntary goal-directed arm movement. On the basis of centre of foot pressure displacement and grip force analysis in lifting while standing, Jucaite et al. ${ }^{9}$ showed that, although children with DCD initiated postural adjustments before lifting the object, they did so with delayed timing. Furthermore, postural adjustments presented less consistent adaptation to the weight of the lifted object in children with DCD than in comparison individuals. In short, it seems that children with $D C D$ encounter difficulties in the predictive modelling of APAs.

Both perceptual and motor processing have been reported to be impaired in children with DCD. However, according to Wilson et al, ${ }^{10}$ DCD originates from a deficit in the internal modelling of action, which could explain the reduced ability of these children to produce an accurate forward model for prospective actions and APAs. Forward models use the efference copy to anticipate and cancel the sensory effect of a given movement. They also integrate both sensory and motor information, and therefore rely on intersensory integration (visual, tactile, proprioceptive, etc.).

In this study, we investigated APAs in children with DCD by means of the bimanual load-lifting task, which consisted of the unloading of the forearm by a voluntary movement of the child's other arm. The feedforward control of this coordination relies on both accurate representation of the load and coordination between the arm executing the unloading and the forearm position, to minimize 
the disturbance of the forearm position due to the unloading. A deficit in the internal modelling would then result in imprecise and variable APAs in children with DCD. In addition, the bimanual load-lifting task has the advantage of establishing a clear anatomical distinction between posture and movement (i.e. the 'postural forearm' supporting the load and the arm executing the movement). It also allows the simultaneous study of muscle contribution (EMG) and kinematics, both key indicators of APA.

This paradigm was chosen in an attempt to describe the mechanisms underlying the hypothesized impaired use of APAs in DCD.

\section{METHOD}

Sixteen children with reported motor problems and ages ranging from 5 years 10 months to 12 years 7 months (two females, 14 males; mean 9y; SD 2y) took part in the study at the care units of Timone University Hospital in Marseilles and Toulouse University Hospital. The children's motor performances were assessed by means of motor tests, such as the Lincoln-Oseretsky, ${ }^{11}$ the Charlop-Atwell, ${ }^{12}$ or the Movement Assessment Battery for Children(M-ABC), ${ }^{13}$ all of which have French norms. The children's results were poorer than expected, given their chronological age and intelligence in terms of academic achievement. Furthermore, their coordination problems were serious enough to interfere with academic performance and social integration. All children also met the DSM-IV criteria for DCD. ${ }^{1}$ The $M-A B C^{13}$ was used to test the children before administering the bimanual load-lifting task.

Sixteen age-matched children ranging in age from 5 years 11 months to 13 years (six females, 10 males; mean 9y; SD 2y) constituted the comparison group (typically developing children). All children were receiving normal schooling and there were no reports of motor difficulty. There was no significant difference in age and arm length between the two groups according to the Wilcoxon signed-rank test was or in sex and handedness according to Fisher's exact test. All parents and children gave their informed consent prior to the experiment, which was approved by the local ethics committee. 
The experimental set-up was the same as that described in previous papers. ${ }^{14}$ The bimanual load-lifting task consists of a comparison between the imposed and voluntary unloading of a load placed on the participant's forearm. The children were seated on a chair equipped with a support to which the nonpreferred arm could be fixed vertically just above the elbow. The load was attached to this 'postural' arm, either below or on top of the forearm, via a metallic wrist band equipped with a strain gauge. Following the scaling determined in previousstudies, ${ }^{14}$ the weight of the load was $300 \mathrm{~g}$ for children aged $5-6$ years, $350 \mathrm{~g}$ for children aged 7 to 8 years, $400 \mathrm{~g}$ children aged 9-11 years, and $450 \mathrm{~g}$ for children aged 12 to 13 years. Before each trial, children were asked to place their postural forearm in a horizontal and semi-prone position. In the imposed unloading situation, the load suspended below the postural forearm was unpredictably released by the experimenter by breaking an electromagnetic circuit. The unpredictable load release triggers an elbow flexion accompanied by an unloading reflex on the flexor muscles of the postural forearm. ${ }^{14}$ In the voluntary unloading situation, the load placed on the upper part of the postural forearm was lifted by the child using his or her contralateral hand. A reduced elbow flexion and reduced EMG activity on the flexor muscles, starting before the onset of unloading, indicated the use of APA. The procedure consisted of 10 trials in the imposed situation, followed by 10-15 trials in the voluntary situation. The effect of order has been tested in this protocol ${ }^{14}$ and does not affect comparisons between the two situations.

The force exerted by the load on the postural forearm and the angular postural elbow displacement signals were recorded, digitalized, and stored on a computer disk for analysis, along with the EMG signals (sampling rate $500 \mathrm{~Hz}$ ). Each trial was viewed offline on a monitor screen. Using a semi-automated program that enables visual adjustments, developed in our laboratory (Matlab 5.2, Mathworks) [MB4] the onset of unloading $\left(t_{0}\right)$ was defined as the time of the first maximal value of the second derivative of the force signal transmitted by the gauge. The upwards movement of the postural forearm was quantified both in the imposed and the voluntary conditions. We measured maximum angular 
amplitude (MA), maximum velocity (MV), and their corresponding latencies. In the voluntary unloading session, the MA and MV for each trial were expressed as a percentage of the mean value obtained from each child in the imposed unloading session (MA\% and MV\%). As such, MA\% and MV\% expressed postural stabilization performances during voluntary unloading.

Bipolar surface electrodes (surface area $2.5 \mathrm{~mm}^{2}$ ) were placed over thesurface of the biceps brachii and brachioradialis postural elbow flexors. EMG signals were recorded with a TELEMG multichannel electromyograph (BTS Bioengineering, Padova, Italy), amplified, rectified, filtered $(10-200 \mathrm{~Hz}$ band pass), and integrated with a $10 \mathrm{~ms}$ time constant. In the imposed unloading condition, the latency and duration of the reflex inhibition were measured. In the voluntary unloading condition, changes in the level of activity occurring at $t_{0} \pm 100 \mathrm{~ms}$ were measured (latency and duration). Within this time window, inhibition and activation occurring before $t_{0}+50 \mathrm{~ms}$ were deemed to be anticipated. ${ }^{14}$

Most of the data analysis was performed using the mean value obtained for each child. These mean values were then treated as single independent observations. The Wilcoxon signed-rank test was then used to compare performances between the voluntary and imposed unloading situations and to compare children with and without DCD. Pearson's correlation coefficient was used to measure the correlation between the M-ABC score and the postural performances, and between age and postural performances. The analysis of the influence of the flexor inhibition latency on postural stabilization during voluntary unloading (as expressed by MA\%) was completed across the entire set of trials for each child. This data structure, in which several individuals were assessed more than once, required a specific regression procedure. A generalized linear model (Gaussian distribution and identity link function) estimated by a generalized estimating equation procedure with an independent correlation matrix was used. ${ }^{15}$ This approach takes the conditional dependencies between observations into account and provides unbiased standard error of the 
linear regression coefficients. Differences with a $p$ value $<0.05$ were considered to be statistically significant.

\section{RESULTS}

\section{Postural stabilization and M-ABC impairment score}

According to the M-ABC manual, ${ }^{13}$ DCD is indicated when the impairment score is at or below the 5th centile, whereas 'borderline $D C D$ ' is indicated when the score is between the 5th and 15th centiles. In this study, nine children scored below the 5th centile (S1 to S9), three children between the 5th and 15th centiles (S10 to S12), and four children above the 15th centile (S13 to S16). Figure 1 shows box plots representing key values of MA\% for each child and his or her age-matched peer. The correlation between the M-ABC score and MA\% was not significant.

The median values and quartiles of MA\% were $36 \%(32-42 \%)$ in children with confirmed DCD, 22\% (20-23\%) in children with 'borderline DCD', and $26 \%$ (24-27\%) in children with reported motor problems but who scored above the 15th centile. The median values and quartiles of their age-matched typically developing peers were 19\% (12-27\%), 12\% (11-17\%), and 17\% (13-23\%), respectively.

Taking into account the large difference between the three groups of children with reported motor problems, and in order to focus on 'children with confirmed $D C D$, the subsequent analysis was conducted only in children with an M-ABC score below the 5th centile. This group thus comprised the children with a reported motor problem who scored below the 5th centile on the M-ABC ( $n=9$; two females, seven males; age range 5 y $10 \mathrm{mo}$ to $12 \mathrm{y} 4 \mathrm{mo}$ ) and their agematched typically developing peers ( $n=9$; four females, five males; age range $5 y 11 \mathrm{mo}$ to $11 \mathrm{y} 10 \mathrm{mo}$ ). The mean age of each group was 8 years 5 months. Differences in age, arm length, sex, and handedness between children with and without DCD were not significant.

\section{Imposed unloading}


The imposed unloading was followed by an upward flexion of the postural forearm and by an unloading reflex characterized by flexor muscle inhibition. The latency and duration of this inhibition, measured on the biceps brachii and brachioradialis, did not differ significantly between the two groups of children (Table I). The difference between children with DCD and the typically developing children was not significant for the absolute values of MA and MV during imposed unloading (Table II).

\section{Voluntary unloading}

As observed in typically developing children in a previous study, ${ }_{1}^{14}$ the elbow rotation following voluntary unloading was smaller than that following imposed unloading in children with DCD. The absolute value of MA was lower ( $t=45$, $p=0.004)$ and its latency shorter $(t=45, p=0.004)$ during voluntary unloading than during imposed unloading. MV was also reduced $(t=43, p=0.01)$ and its latency longer $(t=3, p=0.02)$ during voluntary unloading than during imposed unloading.

$M A \%$ and $M V \%$ were significantly higher in children with DCD than in typically developing children (Table II). MA and MV latencies did not significantly differ between the two groups $(178 \mathrm{~ms}$ and $89 \mathrm{~ms}$, respectively, in children with $D C D$, and $154 \mathrm{~ms}$ and $91 \mathrm{~ms}$, respectively, in typically developing children).

The activity measured on the biceps brachii decreased either before or concomitantly with the onset of voluntary unloading (Table I). This inhibition started earlier and lasted longer in the voluntary situation than in the imposed one for both groups of children. Neither the latency nor the duration of the biceps brachii inhibition differed significantly between the two groups. The inhibition measured on the brachioradialis started earlier in the voluntary situation than in the imposed one in both groups. However, in children with DCD, inhibition duration was not significantly longer for the voluntary unloading than it was for the imposed unloading. During voluntary unloading, brachioradialis inhibition latency was shorter in typically developing children than in children with DCD. 
A previous study had demonstrated that the timing of inhibition is a key factor for APA performance. ${ }^{14}$ In this study, we investigated the link between MA\% and the onset of postural flexor inhibition with a generalized estimating equation. For the biceps brachii, the standardized coefficient of regression showed a positive and significant effect of the onset of inhibition on $M A \%$ in typically developing children $(\beta=0.39, p=0.007)$ but not in children with $\mathrm{DCD}$ $(\beta=-0.05, p=0.74)$. For the brachioradialis, a similar result was found $(\beta=0.38$, $p<0.001$, and $\beta=0.03, p=0.89$; Fig. 2 ).

The effect of age was tested in children with and without DCD for each variable using Pearson's correlation coefficient. Despite the participants' broad age range, age was not a contributing factor to any of the results.

\section{DISCUSSION}

\section{Developmental coordination disorder, M-ABC score, and postural stabilization}

In the first part of this study, we showed that the diagnosis of DCD is still problematic. ${ }^{16}$ The assessment of DCD relies on an individually administered norm-referenced test. In France, many physiotherapists still refer to French versions of the Lincoln-Ozeretsky ${ }^{11}$ or of the Charlop-Atwell ${ }^{12}$ motor scales. Because the $\mathrm{M}-\mathrm{ABC} \mathrm{C}^{13}$ has been described as the best instrument and facilitates international communication, we added this test to our protocol and observed that some of the selected children scored above the 15th centile. This phenomenon has been reported previously, ${ }^{17}$ and one possible explanation for this may be that none of the existing tests of motor function covers the whole range of motor abilities. It is, however, important to stress that a specific test and a cut-off point for inclusion should always be clearly determined, and that clumsy children scoring above the 15 th centile deserve further exploration.

Contrary to the findings of Cherng et al., ${ }^{5}$ the correlation between the M-ABC score and postural stabilization was not significant in this study. However, despite the small group size, children scoring between the 5th and the 15th 
centile tended to present lower values of MA\% than children scoring below the 5 th centile. These children with 'borderline $D C D$ ' also seemed to be more efficient in maintaining postural forearm stability during the task. Further investigations should help researchers and clinicians to explore the status and development of these 'at risk for DCD' children.

\section{Unloading reflex in children with DCD}

Both kinematic and EMG data indicated that the unloading reflex during imposed unloading was the same in both groups of children. Other studies using this paradigm have found that this reflex is intact in children with Duchenne muscular dystrophy ${ }^{18}$ and autism, ${ }^{19}$ but not in deafferented individuals. ${ }^{20}$ This result confirms that the proprioceptive afference and motor efference that constitute the unloading reflex are not impaired in DCD.

\section{Postural anticipation in children with DCD during voluntary unloading} It appears from our study that APAs are present in children with DCD, just as they are in typically developing children. ${ }^{14}$ The decrease in both maximum elbow rotation and maximum angular velocity during voluntary unloading compared with imposed unloading indicates the presence of voluntary control of postural stabilization. Furthermore, the early inhibition of the elbow flexors within the anticipatory window (i.e. before $t_{0}+50 \mathrm{~ms}$ ) confirms that postural stabilization was made possible by the use of an anticipatory mode of control.

However, despite the presence of APAs, forearm stabilization during voluntary unloading was poorer in the DCD group than in the typically developing group. The anticipatory control of posture was not as efficient in children with DCD as it was in typically developing children. This result is in line with other studies exploring APA during arm pointing ${ }^{8}$ or in a voluntary load-lifting task while standing. ${ }^{9}$

Under normal circumstances, the initiation of voluntary unloading triggers the onset of a precisely organized sequence of muscle activation and inhibition in the postural forearm. ${ }^{6}$ Using the same task, Schmitz et al. ${ }^{14}$ demonstrated that 
precise mastering of timing parameters is one of the key factors in the development of APA during childhood. Our results show that the timing of the muscular events on the brachioradialis, but not on the biceps brachii, was affected in children with DCD compared with typically developing children. This may contribute to the impaired postural stabilization observed in children with DCD. Inconsistent timing of muscle activation sequences and an atypical profile of muscle activation patterns have been reported in children with DCD. ${ }^{2-4,8,21}$ Given that development proceeds in a proximodistal manner, the delayed inhibition of the distal muscle (brachioradialis) only, as observed in this study, argues in favour of a maturational delay in the development of APA control in children with DCD.

\section{From flexor inhibition to postural stabilization}

The bimanual load-lifting task makes it possible to calculate the coefficient of regression between the onset of flexor's inhibition and postural stabilization. This effect was positive and significant in typically developing children: the earlier the onset of inhibition, the better the forearm stabilization. Interestingly, we did not find this link for either of the muscles in children with DCD. When Geuze $^{2}$ analysed the correlation between EMG activation and ground reaction force in the one-leg stance, he also observed a weaker coupling in children with DCD than in typically developing children. We assume that the poor predictive modelling of force-time parameters of APA lies behind the weak efficiency of postural control in children with DCD.

Returning to the computational approaches to motor control, our results support the internal modelling deficit hypothesis ofDCD. ${ }^{10}$ First, peripheral sensory and motor function appeared to be preserved in children with $D C D$, in so far as the unloading reflex was similar in typically developing children and in children with DCD. Furthermore, children with DCD were able to produce APAs and presented anticipatory muscle inhibitions and reduced forearm flexion during voluntary unloading. However, the feedforward planning of the postural component of the action was not as consistent with the task goal in children with $D C D$ as it was in typically developing children. The onset of brachioradialis 
inhibition was delayed in the former group compared with the latter; there was no link between muscle inhibition onset and forearm stabilization in children with $\mathrm{DCD}$, unlike typically developing children, and forearm stabilization was poorer in the former than in the latter. Poor predictive modelling may have stemmed from the impaired integration of kinaesthetic and visuomotor feedback concerning the object's weight, the onset of unloading and the temporal and spatial coordination between both arms. As a result, bimanual coordination during the unloading task appeared imprecise and immature in children with DCD.

\section{CONCLUSION}

The bimanual load-lifting task relies on a precise forward model of prospective action coordinating movement and posture, and requires a carefully orchestrated sequence of postural muscle activations and inhibitions. ${ }^{6}$ In this study, the impaired fine-tuning of the muscle contribution and the poor performances on postural stabilization argue in favour of an impaired predictive modelling in DCD. ${ }^{10}$ Note, however, that the children from this study underwent a definite classification of DCD and that a closer look at the individual kinematic data reveals that not all children exhibited an impairment of APA in this task.

The characteristics of APA observed in this study are indicative of an immature anticipatory control of posture in children with DCD scoring below the 5thcentile. The immature aspect of motor coordination or function in the latte rhas already been reported. ${ }^{22,23}$ However, in contrast to other neurodevelopmental disorders, spontaneous recovery from DCD may occur duringadolescence. ${ }^{24,25}$ This study was initially designed to investigate the development of children with DCD, but our results do not yield any developmental conclusion. We believe that longitudinal studies are now needed to track developmental trends in these children. Such research would probably help to better understand the important variability observed in children with DCD. 
Finally, APAs should also be investigated in children or adolescents with reported motor difficulties who score above the 5th or 15th centile on the $\mathrm{M}$ $A B C .{ }^{13} \mathrm{~A}$ better understanding of the two $\mathrm{DCD}$ developmental pathways (persistence or resolution) ${ }^{24}$ should, at last, help us to determine whether DCD results from a maturational delay or from a specific dysfunction of the internal model of the motor system.

\section{ACKNOWLEDGEMENTS}

The authors are grateful to all the children and their parents who took part in this study. They also thank Dr F Brun, Professor Y Chaix, and Dr J-M Albaret for their valuable contributions to recruiting individuals with $D C D$, $\operatorname{Dr} B$ Dauvier for statistical assistance, and E Portier for revising the English version of the manuscript. This study was supported by grants from the French National Centre for Scientific Research (CNRS).

\section{REFERENCES}

1. American Psychiatric Association. Diagnostic and statistical manual of mental disorders: DSM-IV-TR. 4th edn. Washington: American Psychiatric Association, 2000.

2. Geuze RH. Postural control in children with developmental coordination disorder. Neural Plast 2005; 12: 183-96.

3. Williams $\mathrm{H}$, Fisher J, Tritschler K .Descriptive analysis of static postural control in 4, 6, and 8 year old normal and motorically awkward children. Am J Phys Med 1983; 62: 12-26.

4. Geuze RH. Static balance and developmental coordination disorder. Hum Mov Sci 2003; 22: 527-48.

5. Cherng R, Hsu Y, Chen Y, Chen J. Standing balance of children with developmental coordination disorder under altered sensory conditions. Hum Mov Sci 2007; 26: 913-26.

6. Massion J. Movement, posture and equilibrium: interaction and coordination. Prog Neurobiol 1992; 1: 35-56. 
7. Przysucha EP, Taylor MJ, Weber D. The nature and control of postural adaptations of boys with and without developmental coordination disorder. Adapt Phys Activ Q 2008; 25: 1-16.

8. Johnston LM, Burns YR, Brauer SG, Richardson CA. Differences in postural control and movement performance during goal directed reaching in children with developmental coordination disorder. Hum Mov Sci 2002;

21: $583-601$.

9. Jucaite A, Fernell E, Forssberg H,Hadders-Algra M. Deficient coordination of associated postural adjustments during a lifting task in children with neurodevelopmental disorders. Dev Med Child Neurol 2003; 45: 731-42.

10. Wilson PH, Butson M. Deficits underlying DCD. In: Geuze RH, editor(s). Developmental coordination disorder: a review of current approaches. Marseilles: Solal, 2007: 111-37.

11. Sloan W. The Lincoln-Oseretsky motor development scale. Genet Psychol Monogr 1955; 51: 183-252.

12. Charlop, M, Atwell, CW. The Charlop-Atwell Scale of Motor Coordination: a quick and easy assessment of young children. Percept Mot Skills1980; 50: 1291-308.

13. Henderson S, Sugden D. Movement assessment battery for children. London: Psychological Corp., 1992.

14. Schmitz C, Martin N, Assaiante C. Building anticipatory postural adjustment during childhood: a kinematic and electromyographic analysis of unloading in children from 4 to 8 years of age. Exp Brain Res 2002; 142: 354-64.

15. Liang KY, Zeger SL. Longitudinal data analysis using Generalized Linear Models. Biometrika 1986; 73: 13-22.

16. Wann J. Recognizing problems in movement coordination. Dev Med Child Neurol 2008; 50: 806.

17. Geuze RH, Jongmans MJ, Schoemaker MM, Smits-Engelsman BC. Clinical and research diagnostic criteria for developmental coordination disorder: a review and discussion. Hum Mov Sci 2001; 20: 7-47. 
18. Jover M, Schmitz C, Bosdure E, Chabrol B, Assaiante C. Anticipatory postural adjustments in a bimanual load-lifting task in children with Duchenne muscular dystrophy. Neurosci Lett 2006; 403: 271-5.

19. Schmitz C, Martineau J, Barthelemy C, Assaiante C. Motor control and children with autism: deficit of anticipatory function? Neurosci Lett 2003; 348: 17-20.

20. Forget $R$, Lamarre $Y$. Anticipatory postural adjustment in the absence of normal peripheral feedback. Brain Res 1990, 508: 176-9.

21. Raynor A. Strength, power, and co-activation in children with developmental coordination disorder. Dev Med Child Neurol 2001; 43: 676-84.

22. Pereira HS, Landgren M, Gillberg C, Forssberg H. Parametric control of fingertip forces during precision grip lifts in children with $D C D$ (developmental coordination disorder) and DAMP (deficits in attention motor control and perception). Neuropsychologia 2001; 39: 478-88.

23. de Castelnau P, Albaret JM, ChaixY, Zanone PG. A study of EEG coherence in DCD children during motor synchronization task. Hum Mov Sci2008; 27: $230-41$.

24. Cantell MH, Smyth MM, Ahonen TP. Two distinct pathways for developmental coordination disorder: persistence and resolution. Hum Mov Sci 2003; 22: 413-31.

25. Visser J, Geuze RH, Karlverboer AF. The relationship between physical growth, the level of activity and the development of motor skills in adolescence: differences between children with DCD and controls. Hum Mov Sci1998; 17: 573-608. 
Table I: Median values and quartiles of the latency and duration of the inhibitions occurring on the biceps brachii and the brachioradialis during voluntary and imposed unloading in children with DCD and typically developing children.

\begin{tabular}{|c|c|c|c|c|c|c|}
\hline & \multicolumn{3}{|c|}{ Inhibition latencies (ms) } & \multicolumn{3}{|c|}{ Inhibition duration (ms) } \\
\hline & $\begin{array}{l}\text { Typically } \\
\text { developing } \\
\text { children }\end{array}$ & $\begin{array}{l}\text { Children with } \\
\text { DCD }\end{array}$ & $\begin{array}{l}\text { Group } \\
\text { comparison }\end{array}$ & $\begin{array}{l}\text { Typically } \\
\text { developing } \\
\text { children }\end{array}$ & $\begin{array}{l}\text { Children with } \\
\text { DCD }\end{array}$ & $\begin{array}{l}\text { Group } \\
\text { comparison }\end{array}$ \\
\hline \multicolumn{7}{|c|}{ Biceps brachii } \\
\hline $\begin{array}{l}\text { Imposed } \\
\text { unloading }\end{array}$ & $\begin{array}{l}54.3(52.4, \\
60.4)\end{array}$ & $\begin{array}{l}52.8(50.3, \\
58.6)\end{array}$ & $\begin{array}{l}n s(t=21, \\
p=0.74)\end{array}$ & $\begin{array}{l}38.5(35.8, \\
41.6)\end{array}$ & $37(35.3,49.5)$ & $\begin{array}{l}n s(t=22, \\
p=0.64)\end{array}$ \\
\hline $\begin{array}{l}\text { Voluntary } \\
\text { unloading }\end{array}$ & $\begin{array}{l}-4.4(-36.9 \\
4.6)\end{array}$ & $\begin{array}{l}-0.2(-8.8 \\
17.8)\end{array}$ & $\begin{array}{l}n s(t=24, \\
p=0.46)\end{array}$ & $71(61.6,87.9)$ & $80(74.6,82.5)$ & $\begin{array}{l}n s(t=21, \\
p=0.74)\end{array}$ \\
\hline $\begin{array}{l}\text { Condition } \\
\text { comparison }\end{array}$ & $t=36, p=0.01$ & $t=45, p=0.004$ & & $t=0, p=0.01$ & $t=3, p=0.02$ & \\
\hline \multicolumn{7}{|c|}{ Brachioradialis } \\
\hline $\begin{array}{l}\text { Imposed } \\
\text { unloading }\end{array}$ & $\begin{array}{l}56.4(55.2 \\
60.9)\end{array}$ & $\begin{array}{l}62.3(58.3, \\
63.1)\end{array}$ & $\begin{array}{l}n s(t=16, \\
p=0.31)\end{array}$ & $\begin{array}{l}55.5(51.3, \\
63.0)\end{array}$ & $\begin{array}{l}45.38(43.5, \\
48.53)\end{array}$ & $\begin{array}{l}n s(t=3, \\
p=0.16)\end{array}$ \\
\hline $\begin{array}{l}\text { Voluntary } \\
\text { unloading }\end{array}$ & $\begin{array}{l}-24.4(-36.4 \\
3.2)\end{array}$ & $22(0,36.6)$ & $t=32, p=0.05$ & $\begin{array}{l}73.4(64.7 \\
82.8)\end{array}$ & $\begin{array}{l}64.4(55.3 \\
88.6)\end{array}$ & $\begin{array}{l}n s(t=15, \\
p=0.74)\end{array}$ \\
\hline $\begin{array}{l}\text { Condition } \\
\text { comparison }\end{array}$ & $t=28, p=0.02$ & $t=36, p=0.01$ & & $t=2, p=0.05$ & $\begin{array}{l}n s(t=12, \\
p=0.46)\end{array}$ & \\
\hline
\end{tabular}

Comparisons were performed using the Wilcoxon signed-rank test. DCD, developmental coordination disorder; ns, not significant. 
TableII: Median values and quartiles of maximum amplitude (MA) and maximum velocity (MV; expressed in both absolute values and percentages) of the forearm flexion during voluntary and imposed unloading in children with DCD and typically developing children

\begin{tabular}{llll}
\hline & Typically developing children & Children with DCD & Group comparison \\
\hline MA & $7.9(7.5,8.9)$ & $6.7(6.3,7.1)$ & $n s(t=12, p=0.25)$ \\
Imposed unloading & $1.4(1.12)$ & $2.6(2.32 .9)$ & $t=40, p=0.04$ \\
Voluntary unloading & $19.9(15.2,21.1)$ & $36.5(32.6,42.5)$ & $t=43, p=0.01$ \\
MA\% & & & $n s(t=12, p=0.25)$ \\
MV & $71(59.8,76.9)$ & $55(50.6,62.2)$ & $n s(t=38, p=0.07)$ \\
Imposed unloading & $23.7(16.4,30.5)$ & $40.4(30.5,43.4)$ & $t=42, p=0.02$ \\
Voluntary unloading & $34.3(29.2,37.1)$ & $64.9(44.8,79.9)$ & \\
MV\% & & &
\end{tabular}

Comparisons were performed using Wilcoxon signed-rank tests. DCD, developmental coordination disorder; ns, not significant. 
Figure1: Box plots representing maximum amplitude percentage (MA\%) in children with reported motor problems (grey boxes) and age-matched typically developing children (white boxes) during voluntary unloading: means (cross),medians (bold line), quartiles (box lower and upper side), and extreme values.S1 to S9, Movement Assessment Battery for Children (M-ABC) score below the 5th centile; S10 to S12, M-ABC score between the 5th and 15 th centiles; S13 to S16, $\mathrm{M}-\mathrm{ABC}$ score above the 15 th centile. Children were sorted by age within each of the three groups.

Figure 2: Graphic representation of maximum amplitude percentage (MA\%) as a function of flexor inhibition latency for each trial (top: biceps brachii; bottom: brachioradialis) in typically developing (TD) children (white dots) and children with DCD (black dots). Standardized coefficients of regression and associated probabilities were calculated with a generalized estimating equation. 